\title{
9. Women and Sports
}

\section{INDIAN WOMEN IN SPORTS: MERITS AND DEMERITS}

Anand Babu Pidakala, ${ }^{1}$ N Kumutha ${ }^{2}$ COA, NTPC Ltd, Noida, Uttar Pradesh, India; ${ }^{2}$ Ministry of Defence, New Delhi, India

10.1136/bjsm.2010.078725.207

In these modern times there has been an increasing trend of women participation in sports, particularly in India. However, besides their participation and achievements in sports, it felt that the extent of women participation in sports shall also be addressed. Most of the literature reviewed and government authorities promote only the merits of sports for women by which they are motivated to participate in sports. Their participation in sports also has some damaging effects on family and relationships, children which were addressed very little in few literatures. In my view, the one who experiences these effects only can address in a better way. So, an attempt is made in this paper to study and bring out these issues. The primary purpose of this study is to appreciate and encourage the women participating in sports without damaging their family and relationships and not neglecting children. Also it emphasises on the merits and demerits arising out of Indian women participating in sports, the effects of poor parenting on children and its effect on the society; alerts all men regarding the damaging effects that would come across in married life with women in sports; advices those women to understand the sufferings being experienced by any family member because of their improper planning of priorities of their ambitions. To minimise these damaging effects on society few additional mandatory checks to be incorporated during the selection process of women in sports are also suggested in this paper for recommendations. 